\title{
Pediatric wheelchair athletics: sports injuries and prevention
}

\author{
P E Wilson MD, ${ }^{1} \mathrm{R}$ L Washington $\mathrm{MD}^{2}$ \\ ${ }^{1}$ Department of Rehabilitation Medicine, University of Colorado Health Sciences Center, \\ Box C243, 4200 E Ninth Avenue, Denver, Colorado 80262, USA and Department of \\ Pediatrics, The Children's Hospital, Denver, Colorado, USA $;{ }^{2}$ Department of Pediatric \\ Cardiology, The Children's Hospital, Denver, Colorado, USA.
}

Two hundred and forty-seven competitors at the 1990 Junior National Wheelchair Games (USA) were surveyed for general information, training techniques, and injury patterns. Eighty-three athletes (34\%) responded to the retrospective survey. Injuries were reported by $97 \%$ of those participating in track, $22 \%$ of the field participants, and $91 \%$ of the swimming competitors. A wide variety of injuries was reported ranging from minor bruises, blisters and abrasions to more serious problems (bladder infections, hyperthermia, and soft tissue injuries). While information-reporting biases may be inherent in this type of study, these data are significant in that they are the first obtained for this specific pediatric population via a systemic scientific approach and not from merely anecdotal information.

Keywords: children; wheelchair sports; competition; training injury.

\section{Introduction}

Competitive wheelchair athletics has roots dating back to 1948 when the first Stoke Mandeville Games were held in England. The original games were designed to facilitate the rehabilitation of veterans. ${ }^{1}$ Since that time the sport has evolved into a sophisticated group of diverse activities.

As the sport has grown, so has the number of young competitors. To ensure equitable competition the National Wheelchair Athletic Association (NWAA) created a junior division in the early 1980s to provide children (6-18 years) with head-tohead competition. Junior athletes are provided with true peer competition by being grouped together according to anatomical disability, gender, and age. The disability classification system consists of the following groups (Table I): class 1 athletes have

Table I Description of the NWAA junior medical classification system as it relates to age, neurological impairment level and adult classification level (see text). Note that each individual class (ie neurological impairment level) is subdivided into four age groups providing an additional developmental equality to the junior system not included in the adult classification system

\begin{tabular}{|c|c|c|c|}
\hline \multirow[t]{2}{*}{ Age group } & \multicolumn{3}{|c|}{ Disability group } \\
\hline & Class 1 & Class 2 & Class 3 \\
\hline A (6-8 years) & $\begin{array}{l}\text { NWAA adult classes } \\
\text { 1a-1c }\end{array}$ & $\begin{array}{l}\text { NWAA adult classes } \\
\quad 2 \& 3\end{array}$ & $\begin{array}{l}\text { NWAA adult classes } \\
\text { 4-6 }\end{array}$ \\
\hline B (9-12 years) & $\begin{array}{l}\text { Cervical spinal level } \\
\text { impairment }\end{array}$ & $\begin{array}{l}\text { Thoracic level impair- } \\
\text { ment (T1-T10) }\end{array}$ & $\begin{array}{l}\text { Impairment below T10 level } \\
\text { (includes amputees) }\end{array}$ \\
\hline C (13-15 years) & $\begin{array}{l}\text { Cervical spinal level } \\
\text { impairment }\end{array}$ & $\begin{array}{l}\text { Thoracic level impair- } \\
\text { ment (T1-T10) }\end{array}$ & $\begin{array}{l}\text { Impairment below T10 level } \\
\text { (includes amputees) }\end{array}$ \\
\hline D (16-18 years) & $\begin{array}{l}\text { Cervical spinal level } \\
\text { impairment }\end{array}$ & $\begin{array}{l}\text { Thoracic level impair- } \\
\text { ment (T1-T10) }\end{array}$ & $\begin{array}{l}\text { Impairment below T10 level } \\
\text { (includes amputees) }\end{array}$ \\
\hline
\end{tabular}


upper extremity impairment, poor balance and are related to the adult NWAA class 1A-1C (ie cervical spinal level impairment); class 2 athletes have normal upper extremities, but paralysis equivalent to thoracic 1-10 neurological levels (adult classes 2 and 3); class 3 athletes also have normal upper extremities, but impaired lower extremities (ie neurological impairment below T10) which includes amputees (adult classes 4, 5 and 6). ${ }^{2}$ In addition each class is broken down into four age groups: A for those 6-8 years, B for those 9-12 years, $\mathrm{C}$ for the 13-15 year olds, and finally $\mathrm{D}$ group 16-18 years old. According to this system a 12 year old quadriplegic would be classed as a J1B ( $\mathrm{J}$ stands for junior classification).

Junior competitive sports is one of the fastest growing areas of wheelchair athletics. Because of the young age of the competitors an increasing concern for sports related injuries and prevention has been raised. Many investigators have reported sports injuries in the able bodied pediatric population $^{3.4}$ and within the adult wheelchair athletic ranks, ${ }^{5.6 .7}$ but little information is available on junior wheelchair competitors.

The purpose of this study was to obtain information from junior athletes concerning their involvement in wheelchair sports and to collect data on the types of injuries incurred. The injury aspect of the survey was limited to three major sports included in national competition (track, field and swimming), although table tennis, archery, weight lifting and slalom are also events at Junior Nationals. The results presented in this paper point out trends in training and injury patterns within the pediatric wheelchair athletic population. We also include information on preventive strategies specific to these athletes.

\section{Methods}

As part of the registration materials a questionnaire was designed and distributed to all potential competitors in the 1990 Junior Wheelchair Nationals. The questionnaire was divided into three sections. The first sought general information such as age and gender, as well as information concerning the quality and quantity of the athlete's involvement in wheelchair sports. The second area dealt with various aspects of an athlete's style of training, and what type of training support was available. The third area of inquiry gathered data on the type of injuries encountered either during training or competition. Those athletes who did not respond to the original questionnaire were queried during on-site registration to complete the same form.

\section{Results}

\section{General information}

Of the 247 competitors at Junior Wheelchair Nationals, 83 completed and returned the questionnaire. Twenty-six females and 57 males responded. The age range was 6-18, with the average age being 12.9 years (Fig 1). The range of disabilities included 53 with spina bifida, 11 spinal cord injured, 5 with poliomyelitis, 5 amputees, 4 with cerebral palsy, and a variety of other handicaps (Table II). When grouped by neurological level and age, as described by the NWAA junior classification system, participation by the responding competitors was distributed as follows (Fig 2): the largest group was class J3B (34\%) followed by J3C (18\%), J3D (13\%), J3A (8\%), J2B (6\%), J2C (5\%), J2D (5\%), J1C (4\%), J2A (4\%), $\mathrm{J} 1 \mathrm{D}(2 \%)$ and $\mathrm{J} 1 \mathrm{~B}(1 \%)$. There were no $\mathrm{J} 1 \mathrm{~A}$ respondents. The mean time in competitive wheelchair sports was 3.1 years (range 1-13 years). The participants listed 23 different types of sports involvement. Track participation was most common at $84 \%$, followed by field at $70 \%$, swimming $42 \%$, basketball $26 \%$, slalom or obstacle

Table II Distribution of responding athletes according to disability $(n=83)$

\begin{tabular}{lc}
\hline Disability & Respondents \\
\hline Spina bifida & $53(64 \%)$ \\
Spinal cord injury & $11(13 \%)$ \\
Poliomyelitis & $5(6 \%)$ \\
Amputee & $5(6 \%)$ \\
Cerebral palsy & $4(5 \%)$ \\
Other & $5(6 \%)$ \\
\hline
\end{tabular}




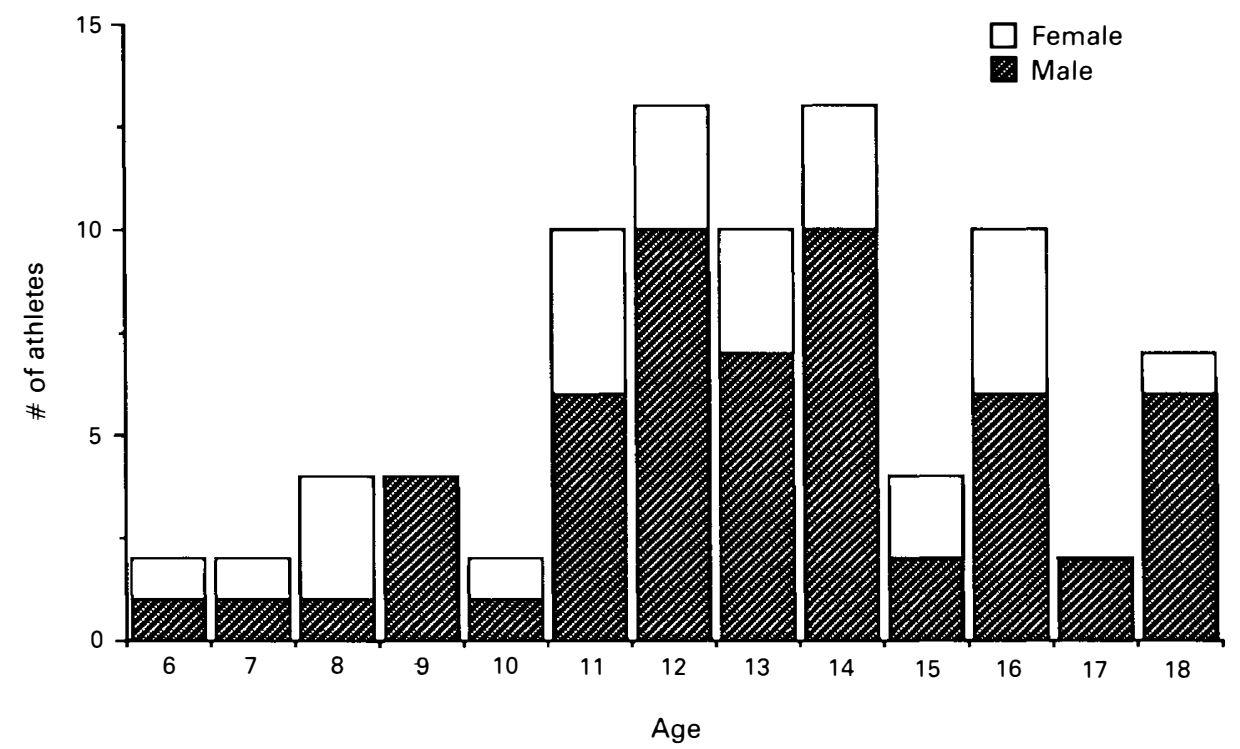

Figure 1 Distribution of responding male and female junior athletes by age and sex. (Total $=83$ respondents: males $=57(69 \%)$, females $=26(31 \%))$.

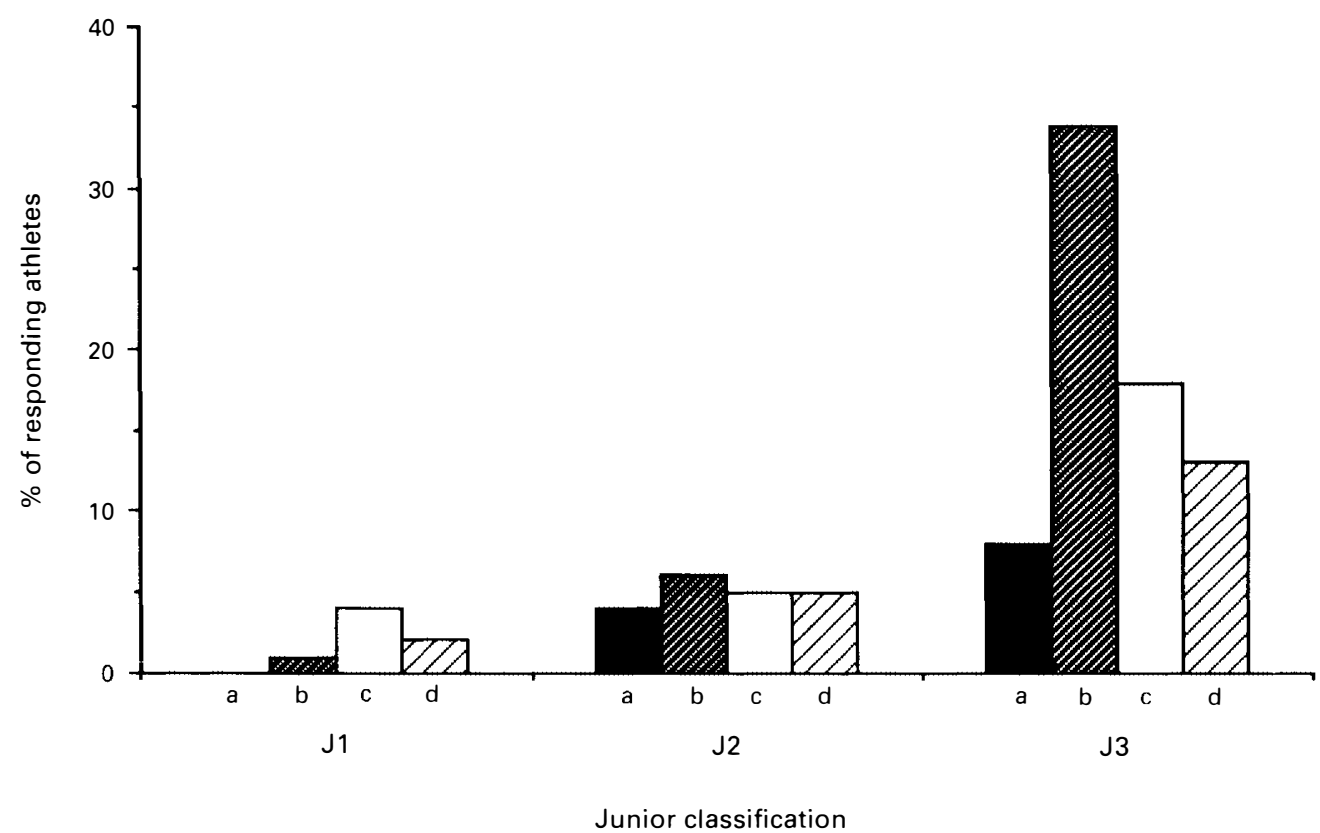

Figure 2 Comparison of all respondents as they are distributed by age and neurological impairment level by the NWAA junior medical classification system. Note that these data show, for this survey, that the preponderance of participants came from the least impaired class (J3). 
courses $21 \%$, tennis $18 \%$, table tennis $15 \%$, road racing $13 \%$, archery $8 \%$, weight lifting $8 \%$, snow skiing $5 \%$ and a variety of other activities at $13 \%$ (Fig 3 ).

\section{Training techniques}

Family members were most often identified as the primary coaching figure $(28 \%)$, next were athletes and physical therapists (both at $25 \%$ ), followed by physical education teachers $(17 \%)$, and others $(5 \%)$. Most athletes trained year-round $(50 \%)$, but an almost equal number trained only before regional competition (47\%) and a small number had no formal training (3\%). Athletes reported that $78 \%$ stretch before workouts, $78 \%$ warm up before work-outs, $74 \%$ cool down after work-outs, and $81 \%$ follow a training schedule. When injured, $82 \%$ reported altering training patterns, either by resting the affected area or cross training, and $62 \%$ use cross training routinely to help prevent injuries.

\section{Sports related injuries}

Of the 69 competitors participating in track, 67 (97\%) reported injuries. The most frequently reported injury was blisters $(77 \%)$, followed by wheelburns $(71 \%)$, hyperthermia or overheating $(49 \%)$, bruising $(41 \%)$, abrasions $(38 \%)$, bladder infections $(22 \%)$, shoulder soft tissue injuries (sprains, strains and tendinitis) (19\%), pressure sores $(14 \%)$, wrist soft tissue injuries $(11 \%)$, fractures $(6 \%)$, and elbow soft tissue injuries (4\%) (Fig 4).

Fifty-eight athletes listed participating in field events, but only 13 reported injuries $(22 \%)$. Of these injuries, blisters were the most frequently reported at $38 \%$, followed by shoulder soft tissue injuries (30\%), wrist soft tissue injuries $(23 \%)$, elbow soft tissue injuries $(7 \%)$, and a collection of other types of injuries (Fig 4).

Swimming had 35 competitors and of these 32 listed injuries $(91 \%)$. The most common injuries were foot scrapes $(94 \%)$ and transfer abrasions (25\%). Hypothermia was reported by $9 \%$ of the athletes and $3 \%$ described shoulder injuries (Fig 4).

\section{Discussion}

Wheelchair athletics involves repetitive use of the upper extremities in training and

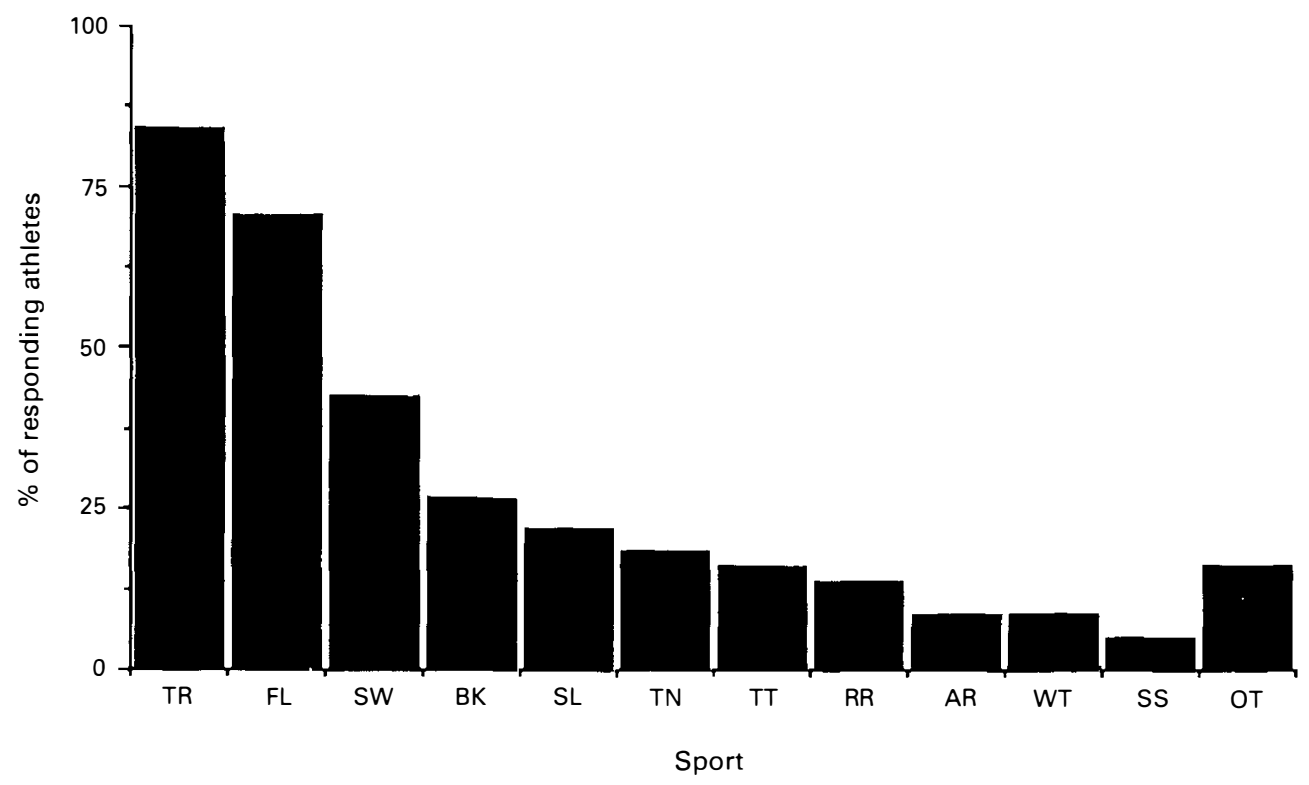

Figure 3 Wheelchair sports involvement. Participation in various reported sports is represented as a percent $(\%)$ of all athletes responding to the survey (total $=83$ ). $\mathrm{TR}=$ track; $\mathrm{BK}=$ basketball; $\mathrm{TT}=$ table tennis; $\mathrm{WT}=$ weight lifting; $\mathrm{FL}=$ field; $\mathrm{SL}=$ slalom; $\mathrm{RR}=$ road $\operatorname{racing} ; \mathrm{SS}=$ snow skiing; $\mathrm{SW}=$ swimming; $\mathrm{TN}=$ tennis; AR = archery; OT = others. 


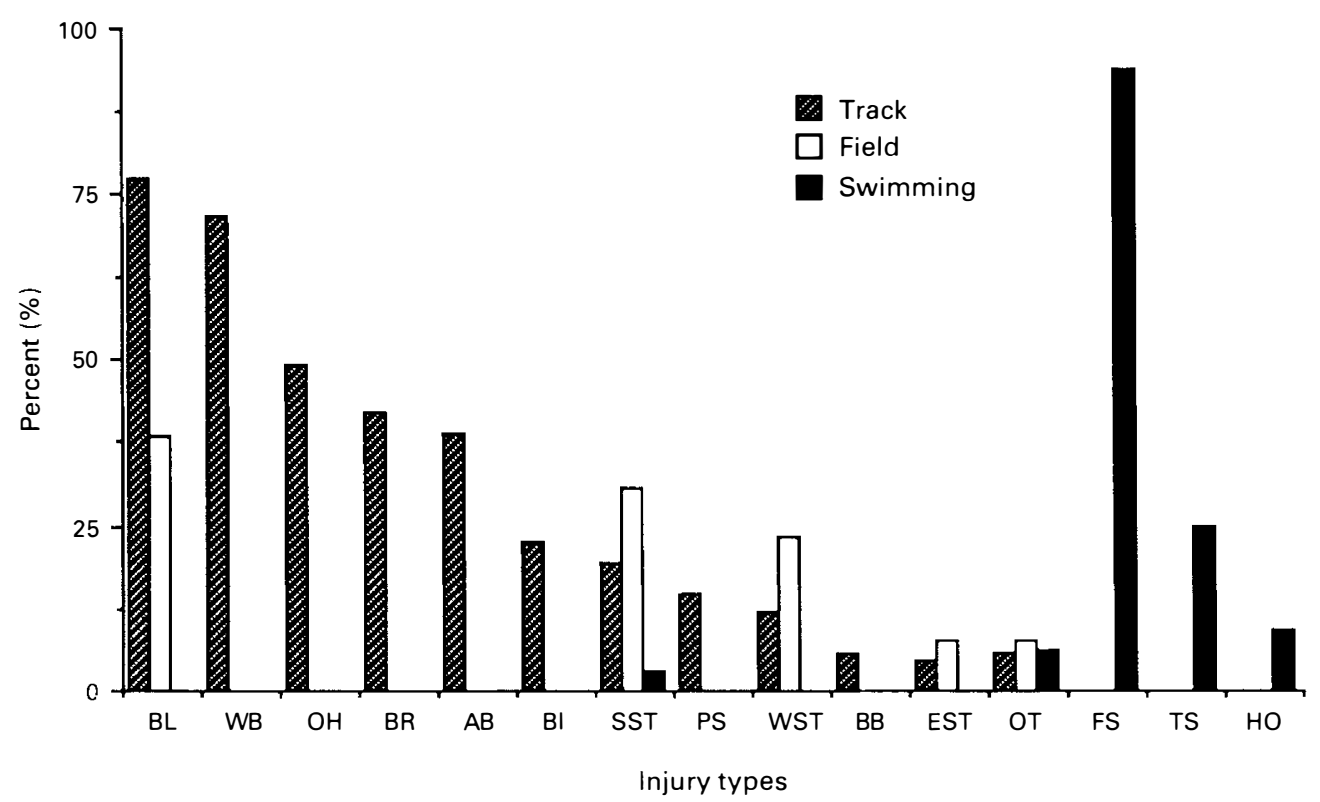

Figure 4 Injuries reported by sport. Injuries reported by each responding athlete are grouped together by injury type and sport in which they occurred. These data are represented as a percent $(\%)$ of those athletes reporting injuries for a given sport. BL = blisters; $\mathrm{BI}=$ bladder infections; EST = soft tissue/elbow; WB = wheel burns; SST = soft tissue/shoulder; OT = other; $\mathrm{OH}=$ overheating; $\mathrm{PS}=$ pressure sores; $\mathrm{FS}=$ foot scrapes; $\mathrm{BR}=$ bruises; WST $=$ soft tissue/wrist; $\mathrm{TS}=$ transfer scrapes $; \mathrm{AB}=$ abrasions $; \mathrm{BB}=$ broken bones $; \mathrm{HO}=$ hypothermia .

competition. Curtis reported in 1985 that $72 \%$ of surveyed adult wheelchair athletes sustained some type of injury since beginning competition. ${ }^{5}$ The most prominent injuries were soft tissue injuries, blisters, and abrasions. In this study, $97 \%$ of the respondents participating in track, $92 \%$ of the swimmers, and $22 \%$ of those involved in field events reported associated injuries. Of these, most were minor injuries such as blisters, wheelburns, abrasions, and bruising.

These minor injuries can be reduced with proper protective equipment and padding. Individuals involved in track can protect hands from blistering with properly taped and fitted gloves. Wheelburns, both on the arms and chest, can be decreased by covering the area with a protective garment such as arm guards. Bruising may be minimized by padding restraining straps, padding bony prominences, and protecting vulnerable areas during transfers. Blisters that occur in field events are more difficult to prevent since gloves are not officially approved. Covering blistered areas until healing occurs and developing callouses during training may decrease this problem. Swimmers have a very high incidence of pool-related abrasions. Wound healing is compromised in this population $^{8}$ and measures to protect the skin should be employed. These measures include placing mats at the poolside to allow for safer transfers, assisting athletes into or out of the pool, and using foot protection.

Other injuries or problems were reported that may be more serious to the competitor. Almost half of all track respondents listed hyperthermia as an associated problem, while $9 \%$ of those swimming listed hypothermia. These two conditions are inherent in this population because of thermoregulatory dysfunction. ${ }^{9}$ The normal mechanisms of temperature control have been interrupted or are altered. Both hypothermia and hyperthermia can have serious complications if the athlete is not given appropriate on-site care. This is even more 
critical in the severely impaired athlete. The best treatment is prevention: train at times appropriate to environmental conditions, drink large quantities of fluid, increase evaporative losses, avoid direct sun, and limit pool time according to the athlete's tolerance.

Other problems directly related to impaired neurological function, such as pressure sores and bladder infections, may be significantly altered by the training process. Sitting for extended periods of time increases the likelihood of developing pressure sores in weight-bearing areas. The popular seating position in a racing wheelchair distributes the bodyweight over a small surface area, thus predisposing the athlete to pressure sores. ${ }^{10}$ Prevention is the key in eliminating this problem with the use of proper cushions and periodic weight shifts.

Bladder infections were reported in $22 \%$ of these athletes. No information was obtained as to the method of bladder management. Factors that increase the likelihood of urinary stasis, such as position in a racing wheelchair, inaccessible bathrooms, and inadequate hydration, produce an environment more favorable for bacterial growth and subsequent infections. ${ }^{11}$

Soft tissue injuries were reported by $34 \%$ of the respondents in track, $14 \%$ in field, and $3 \%$ in swimming. For the purpose of this study soft tissue injuries were defined as sprains, strains and tendinitis. Occurring in decreasing order of frequency were shoulder injuries, wrist injuries, and elbow injuries. The frequency ranking of these injuries is similar to that reported by Ahsoh in his survey of adult wheelchair competitors in the 1987 Oita Marathon. ${ }^{12,13}$ These injuries may reflect overuse syndromes and should be monitored closely to prevent the development of chronic problems.

Of particular concern in the young athlete are certain factors that influence the occurrence of overuse injuries. In the able bodied junior athlete, Micheli identified several risk factors which may be used in a modified form when evaluating injuries in the pediatric wheelchair athlete. ${ }^{3}$ The first factor is improper training technique. We report that $48 \%$ train only before regional competition and $2 \%$ never train. This demonstrates that a large contingent of these children may be involved in the 'weekend warrior' mind set, feeling that they can compete without training time. Poorly conditioned muscles and inflexible joints are prone to overuse syndromes. Coaching personnel need to incorporate this information when scheduling progressive intensity work-outs.

The next risk factor is related to muscle-tendon imbalance. Micheli feels that this imbalance can be either strength, flexibility or bulk effects. ${ }^{3}$ This problem is particularly important in athletes who use the upper extremities exclusively. Since the extensor muscle groups are used predominantly in wheelchair locomotion, these muscles increase in strength and size disproportionally to opposing groups. This results in muscle imbalance and decreased flexibility. Anecdotal evidence indicates that many wheelchair athletes experience decreased flexibility; therefore, this may be one of the key issues in overuse injuries. A strengthening program designed to incorporate oppositional muscle groups may be beneficial in reducing these types of injuries. The data obtained in this survey indicated a high incidence of stretching, warm-up, and warm-down components to daily work-outs. We find this encouraging because these components may help to alleviate some of the overuse injury factors addressed above.

Additionally, the general issue of pediatric sports injuries is confounded by the presence of preexisting medical problems in children with disabilities. For example, a child with an orthopedic disability and limited range of motion is at a much higher risk of injury. Normal body mechanics have to be altered to compensate for the disability. This can cause unusual stress to joints, tendons, and muscles.

Damage to growth-specific areas in the musculoskeletal system, as a result of repetitive stress, is another area of concern. Anatomical sites susceptible to injury are those areas involved in growth, such as the epiphysis, articular surfaces, and tendon apophysis. Overuse injuries have been well documented in the able bodied population, and repetitive actions have been found to cause microtrauma to the skeletal system. ${ }^{14}$ 
The Little League pitcher who is constantly involved in repetitive throwing maneuvers may develop microfractures of the humoral growth plate. ${ }^{15}$ The development of arthritis in adults may be the result of microtrauma to the hips. ${ }^{16}$ Repetitive use has also been implicated in articular cartilage damage resulting in osteochondritis dissecans. ${ }^{17}$ The forces involved in repetitive pushing may have similar consequences in the upper extremities of the wheelchair athletes. Using this information one must then ask: does the repetitive stress of wheelchair athletics predispose the skeletal system of these individuals to traumatic change and possible chronic or arthritic processes later in life?

Using Micheli's risk factors as insight into problems related to overuse, it may be possible to minimize soft tissue injuries and to prevent some chronic problems. In working with these young athletes, training should be toward strengthening, flexibility and conditioning. Physical development and growth spurt activity should be followed and adjustments to training schedules made when appropriate. It may be that children are more susceptible to certain types of injuries during different phases of their growth and development. Further evaluation and study are required to make this determination; however, in the interim medical evaluation of injuries should become part of the routine athletic assessment. The long term effects of athletics on junior wheelchair competitors should be the focus of continued research with a particular emphasis on the prevention of chronic injuries.

This study was conducted to establish a data base on junior wheelchair athletic injuries. However, inherent in this type of study is the possibility of informational bias.
Curtis hypothesized in a survey of adult wheelchair athletes that bias may be attributed to two sources. ${ }^{5}$ First, those athletes who have incurred injuries may be more likely to report problems than non injured athletes. Secondly, the sample of athletes may be skewed towards those individuals "concerned enough about their injuries to report them .... Pediatric populations include another bias in that a third party (parent or coach) may be reporting injuries inaccurately.

This study shows that a significant number of wheelchair participants experienced minor and major injuries during training and competition. We conclude that many of these injuries can be minimized by educating competitors, coaching staff, and alerting medical personnel to the unique problems encountered by junior wheelchair athletes of varying disability and age.

Currently, we do not have information available regarding the long term consequences of participation in competitive wheelchair sports by disabled children. As a result, a long term prospective study of this population has been instituted. This study will attempt to document any correlations between injury and participation in wheelchair sports.

\section{Acknowledgements}

This survey was funded and sponsored by the Department of Pediatrics, The Children's Hospital, Denver, Colorado. The authors would like to acknowledge the Colorado Junior Nationals Committee and Colorado Sports For The Physically Challenged for their support in this endeavor. We would also like to thank Linda Cirnic, MD and the library staff at The Children's Hospital for their comments and editorial advice during the preparation of this manuscript.

\section{References}

1 Strauss R (1984) Sports Medicine. W B Saunders, Philadelphia.

2 Shepard R (1988) Sports medicine and the wheelchair athlete. Sports Med 4: 226-247.

3 Micheli L (1983) Overuse injuries in children's sports: The growth factor. Orthop Clin North Am 14(2): 337-360.

4 Maffulli N (1990) Intensive training in young athletes. The orthopedic surgeon's viewpoint. Sports Med 9(4): 229-243.

5 Curtis K, Dillon D (1985) Survey of wheelchair athletic injuries: Common patterns and prevention. Paraplegia 23: 170-175. 
6 Nilsen R, Nygaard P, Bjorholt P (1985) Complications that occur in those with spinal cord injuries who participate in sport. Paraplegia 23: $152-158$.

7 Jackson R, Fredrickson A (1979) Sports for the physically disabled: The 1976 Olympiad (Toronto). Am J Sports Med 7(5): 293-296.

8 Basson MD, Burney RE (1982) Defective wound healing in patients with paraplegia and quadraplegia. Surg Gynecol Obstet 155(1): 9-12.

9 Glasser RM, Davis GM (1989) Wheelchair dependent individuals. In: DA Franklin, G Seymore, G Tammis, editors. Exercise in Modern Medicine. Williams and Wilkins, Baltimore: 237-267.

10 Corcoran P, Goldman R, Hoerner F, Kling C, Knuttgen H, Marquis B (1980) Sports Medicine and the physiology of wheelchair marathon racing. Orthop Clin North Am 11(4): 697-716.

11 Opitz JL, Thorsteinsson G, Schutt AH, Barrett DM, Olson PK (1988) Neurogenic bladder and bowel. In: J A Delisa, editors. Rehabilitation Medicine, Principles and Practice. J B Lippincott, Philadelphia: 492-518.

12 Ahsoh K (1987) Unpublished data from the 7th Annual Oita Marathon, Oita Japan.

13 Mcann B (1991) The disabled athlete. In: F Mueller, A Ryan, editors. Contemporary Exercise and Sports Medicine Series. FA Davis, Philadelphia: 172-195.

14 Stanitski CL (1988) Management of sports injuries in children and adolescents. Orthop Clin North Am 4: 689-698.

15 Cahill B, Tullos H (1974) Little League shoulder. J Sports Med 2: 150-153.

16 Murray R, Duncan C (1971) Athletic activity in adolescence as etiologic factor in degenerative hip disease. J Bone Joint Surg 53B: 406-419.

17 Adams J (1965) Injuries to the throwing arm: A study of traumatic changes in the elbow joints of boy baseball players. Cal Med 102: 127-132. 